\title{
Aftercare under the 1983 Mental Health Act
}

\author{
Ellen Wilkinson and Hayley Richards
}

The affercare of psychiatric patients discharged from hospltal is currently under debate among clinicians and in the media. Our study cudited the planning of aftercare for defained patients discharged under section 117 of the 1983 Mental Health Act. Our completed audit cycle showed how discharge planning can be improved yef underlines the diticulties encountered in providing for this vulnerable patient group.

Prior to 1983, no statutory provision was made for aftercare of patients discharged from psychiatric institutions. Section 117 of the 1983 Mental Health Act (MHA) introduced and defined formal aftercare. Eligible patients are those discharged from sections $3,37,47$ and 48.

The Mental Health Act Commission (MHAC) has produced Biennial Reports since 1983 commenting on the MHA, including section 117. The first report in 1985 stated: "Plans for the provision of aftercare under section 117 of the Act are in general not far advanced..." The second report in 1987 noted that only $10 \%$ of social services departments had established aftercare policies. Fewer still had mechanisms to ensure review of any continuing need for aftercare. Reasons for this failure were suggested, namely poor liaison, lack of coterminosity between health and social services' boundaries and lack of awareness of the requirements of the Act.

By the third Biennial Report in 1989, the MHAC was still commenting on "patchy implementation of a joint policy", emphasising that responsibility for aftercare could not be evaded by rescinding the section prior to discharge from hospital. To help visiting Commissioners evaluate hospital procedures for section 117, a checklist was included, which recommended a register of currently eligible individuals.

By 1991 and the fourth Biennial Report, most health authorities had completed policies. The issue of overstretched resources was first noted. This report recommended that individual and collective use of resources should be monitored.

The Code of Practice (1990) gives clear guidelines for good practice. It identifies the Responsible Medical Officer (RMO) as instigator of a multi-professional discussion which must take place prior to discharging the patient or granting leave. It clarifies who should participate in the discussion and which issues should be considered. Despite the MHAC recommendation for continuing evaluation of aftercare, there has been no work published concerning section 117 in practice. This study examined aftercare planning for eligible patients in everyday psychiatric practice.

\section{The study}

The study took place in a 244-bed psychiatric teaching hospital, part of a second wave trust, serving a mixed urban/rural catchment area. All patients discharged from the general adult services, subject to section 3 or 37 , were identified from routine documentation.

Two time periods were studied, April 1991 to March 1992 (study one) and October 1992 to September 1993 (study two). Case-notes were scrutinised for demographic details and written evidence of discharge planning, using four minimum standards drawn from the Code of Practice. These standards were:

(a) a case conference with personnel from both health and social services authorities attending

(b) a written careplan defining individual responsibilities and a timescale for action

(c) a key-worker whose responsibilities include coordination and regular review of the careplan

(d) the date for first review of the careplan

The report of the first study was presented to a monthly medical audit meeting in September 1992, when recommendations were made to 
improve practice. These included early identification of eligible patients by medical records staff at the time of detention, immediate and automatic referral to social services, and a colour-coded sheet in the notes, recording all information relating to section 117. A further audit was carried out using the same method, to complete the audit feedback loop.

\section{Findings}

In the first study, there were 27 eligible discharges of which 25 sets of case-notes were available. Twenty-four were discharged from section 3; one from section 37 . The ratio of male to female patients was 1.0:1.6. The mean age was 44 years (range 20-78). The mean duration of compulsory admission was 15 weeks. Six patients (22\%) were discharged to an address outside their admission catchment area.

In the second study, there were 20 eligible discharges, all from section 3 . All case-notes were traced. The ratio of male to female patients was $1: 1$ and the mean age was 42 years (range 19-72). The mean duration of compulsory admission was 18 weeks and only three patients (15\%) changed catchment areas during their stay. Eligible discharges represented $4 \%$ of the total number of discharges from the unit in the first study and $6 \%$ in the second study. On average, each consultant was responsible for coordinating six section 117 discharges per year.

The numbers of discharges meeting each audit standard are given in Table 1. All four standards were met simultaneously by one out of 25 discharges in the first study and by five out of 20 discharges in the second study.

\section{Comment}

Our study audited the quality of aftercare planning as recorded in case-notes; we

Table 1. Standards achieved in aftercare planning

\begin{tabular}{lcl}
\hline Standard achloved & $\begin{array}{l}\text { First study } \\
(\mathbf{n}=25)\end{array}$ & $\begin{array}{l}\text { Second study } \\
(\mathbf{n}=20)\end{array}$ \\
\hline Case conference & $6(24 \%)$ & $10(50 \%)$ \\
Written careplan & $13(52 \%)$ & $15(75 \%)$ \\
Keyworker & $6(24 \%)$ & $10(50 \%)$ \\
Review date & $1(4 \%)$ & $7(35 \%)$ \\
\hline
\end{tabular}

cannot comment on implementation. Using four standards drawn from the Code of Practice, we demonstrated an improvement in documented aftercare planning between the first and second study periods. However, even in the second study, all four standards were met simultaneously by only $25 \%$ of discharges. The proportion of discharges for which a case conference was held increased from $24 \%$ to $50 \%$. It is likely that this increase contributed to the improvements in the other three standards by providing the opportunity to formulate a written careplan, appoint a keyworker from personnel present at the meeting and to agree a review date. Written careplans were found in only one half of all discharges in the first study and in three-quarters of discharges in the second study. This rate is still disappointingly low, and should approach $100 \%$. It is possible that the poor attainment of standards in our audit represents a failure of documentation; for example, case conferences may have been held but not recorded. However, for the purpose of the audit, casenotes remain the best available record of clinical practice.

Even allowing for the improvement between studies, these results support the MHAC, confirming poor implementation of section 117. Local reasons appear to reflect those from the 1987 Biennial Report. In particular, our health district works alongside three separate social services departments, with detrimental effects on liaison. Additional social services teams may also be involved in the $20 \%$ of patients who changed address during admission.

We believe that the audit has effected an improvement in aftercare planning which should lead to an improvement in patient care. Not all of the guidelines suggested following the first study were implemented. However, the audit increased awareness of section 117 and its requirements, and reminded staff of the need for accurate documentation. We found it important to ensure early identification of eligible patients and to convene case conferences in good time prior to discharge.

Our study confirms that we are not yet meeting accepted standards in statutory aftercare, even for the small eligible population in our unit. This fallure has implications for more assertive supervision of vulnerable patients in the community $(\mathrm{DoH}$, 1993) and casts doubt on whether the resources or mechanisms exist to extend a 
similar approach to a much larger population under the care programme approach $(\mathrm{DoH}$, 1990).

The topic of aftercare merits audit in any psychiatric unit caring for detained patients. Larger studies might measure the efficacy of aftercare implementation against 'hard' outcomes such as relapse, readmission or suicide.

\section{References}

Code of Practice, Mental Health Act 1983 (1990) HMSO. DEPARTMENT OF HEALTH (1990) Health and Soclal Services Development 'Carting for People'. The Care Programme Approach for people with a mental Ilness referred to the spectalist psychiatric services. Joint Health/Social Services Circular: HC(90) 23/LASSL (90) 11.
- (1993) Lepislation planned to provide for supervised discharge of poychiatric patients. Press release H93/ 908 Virginia Bottomley announces 10 point plan for developing successful and safe community care. London: DoH.

Mental Henlth ACt Commassion (1985) First Blennial Report HMSO.

- (1987) Second Biennial Report. HMSO.

- (1989) Third Biennial Report. HMSO.

- (1991) Fourth Blennial Report. HMSO.

-Ellen Wilkinson, Registrar in Psychiatry; and Hayley Richards, Registrar in Psychiatry. Blackberry Hill Hospital, Manor Road, Fishponds, Bristol BS16 2EW

*Correspondence

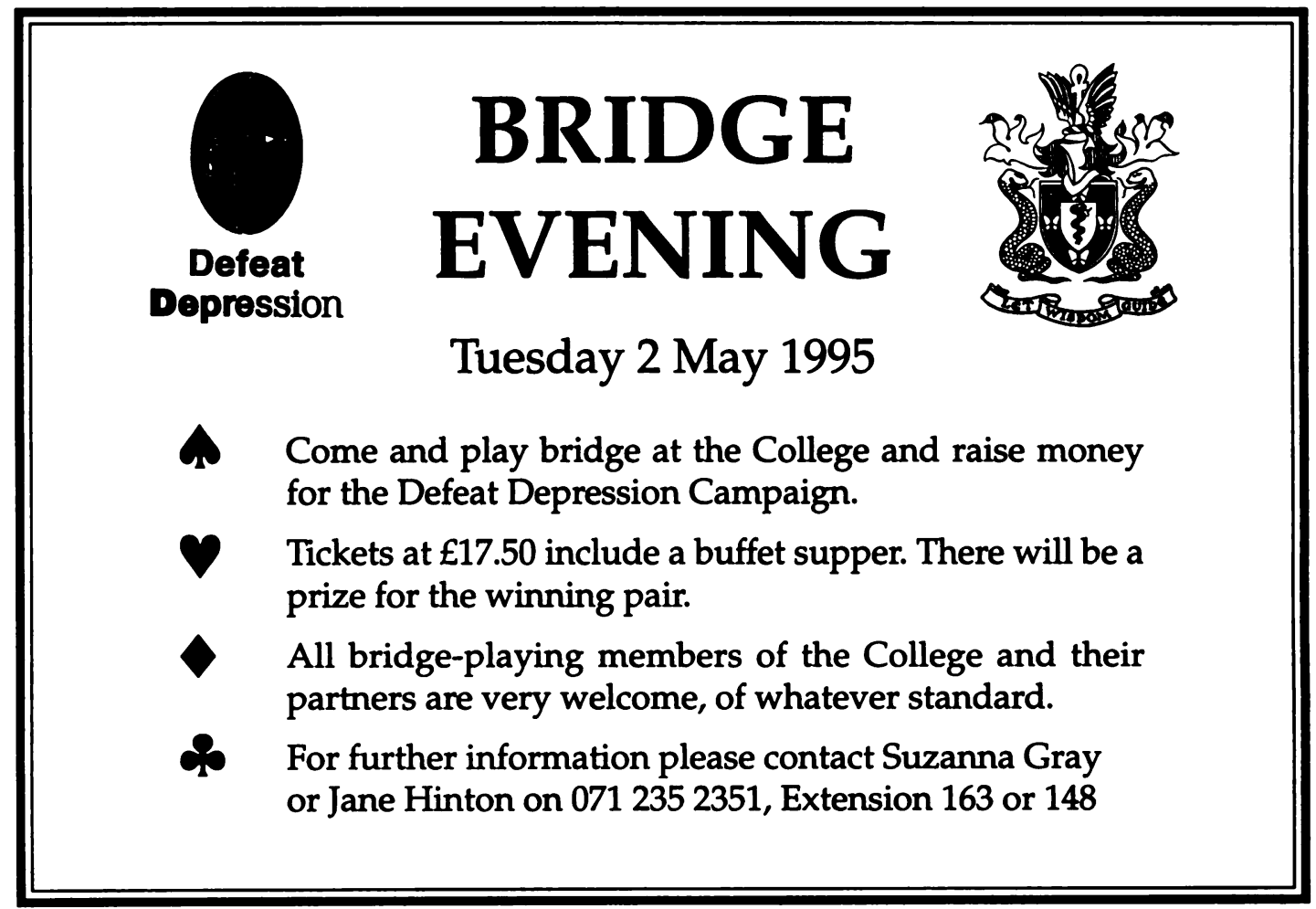

